\title{
Adenovirus encoding XAF-1 and TNF- $\alpha$ in the same open reading frame efficiently inhibits hepatocellular cancer cells
}

\author{
$\mathrm{KAI} \mathrm{LI}^{12^{2 *}}$, XINHONG LI ${ }^{3 *}$, ZHONGJUN WU ${ }^{1}$, LIANSHENG ZHENG ${ }^{4}$, \\ YUQIN CUI ${ }^{2}$, JUN WANG ${ }^{5}$, YIN HUANG ${ }^{2}$ and ZHIHONG YAN ${ }^{2}$ \\ ${ }^{1}$ Department of Hepatobiliary Surgery, Hepatobiliary Treatment Center, \\ The First Affiliated Hospital of Chongqing Medical University, Chongqing 400016; \\ ${ }^{2}$ Department of Oncology, Baotou Cancer Hospital, Baotou, Inner Mongolia 014030; ${ }^{3}$ Department of Medicine, \\ First Affiliated Hospital of Inner Mongolia Medical University, Hohhot, Inner Mongolia 010050; \\ Departments of ${ }^{4}$ Surgical Oncology and ${ }^{5}$ Pharmacy, Baotou Cancer Hospital, Baotou, \\ Inner Mongolia 014030, P.R. China
}

Received April 21,2015; Accepted April 3, 2016

DOI: $10.3892 / \mathrm{mmr} .2016 .5193$

\begin{abstract}
X-linked inhibitor of apoptosis (XIAP)-associated factor 1 (XAF-1), a tumor suppressor, is downregulated in most human malignant tumors. However, the tumor suppressive role of XAF-1 in hepatocellular carcinoma (HCC) and its therapeutic value require further elucidation. The present study examined the expression of XAF-1 at the mRNA and protein level in the $\mathrm{HCC}$ and paired peritumor tissue specimens, as well as in HCC cell lines and a normal liver cell line. A recombinant adenovirus which co-expressed XAF-1 and TNF- $\alpha$ was then constructed, and its effects on the proliferation and colony formation ability of the MHCC $97 \mathrm{H}$ HCC cell line were assessed using apoptosis induction, flow cytometry, trypan blue staining assay and a clonogenic assay. The results demonstrated that the expression of XAF-1 was significantly reduced in HCC tissues compared with that in their matched peritumor specimens, and a significant correlation with the tumor size, stage and tumor - nodes - metastasis stage was identified. The reduced levels of XAF-1 were further confirmed the HCC cell lines MHCC97L, HepG2 and MHCC 97H compared with those in the L02 normal liver cell line. The recombinant adenovirus Ad-XAF-1\&TNF- $\alpha$, which co-expressed XAF-1 and TNF- $\alpha$, was shown to efficiently
\end{abstract}

Correspondence to: Professor Zhongjun Wu, Department of Hepatobiliary Surgery, Hepatobiliary Treatment Center, The First Affiliated Hospital of Chongqing Medical University, 1 Friendship Road, Yuanjiagang, Yuzhong, Chongqing 400016, P.R. China E-mail: zhongjun428@163.com

*Contributed equally

Key words: adenovirus, hepatocellular carcinoma cells, growth, $\mathrm{X}$-linked inhibitor of apoptosis-associated factor 1 , tumor necrosis factor- $\alpha$ express the two proteins at the mRNA and protein level. Furthermore, infection with Ad-XAF-1\&TNF- $\alpha$ synergistically induced apoptosis, reduced the proliferation and colony formation ability of MHCC $97 \mathrm{~L}$ cells to a significantly greater extent than overexpression of XAF-1 or TNF- $\alpha$ individually. To the best of our knowledge, the present study was the first to construct an adenovirus which co-expressed XAF-1 and TNF- $\alpha$ in the same open reading frame and expressed them proportionally. As Ad-XAF-1\&TNF- $\alpha$ inhibited HCC cells with enhanced efficiency, it may be applicable for the treatment of HCC.

\section{Introduction}

Hepatocellular carcinoma (HCC) is one of the most common malignant cancer types worldwide and is accountable for almost 600,000 mortalities each year worldwide (1); it is also has the second highest mortality rate amongst all cancer types in China (2). The main risk factors for HCC development include chronic hepatitis $\mathrm{B}$ and $\mathrm{C}$ infection, alcohol abuse and aflatoxin intake $(3,4)$, as they induce liver cirrhosis, from which $80 \%$ of HCCs are derived (5). Activation of oncogenes and inactivation of tumor suppressor genes have been identified to be associated with carcinogenesis and progression of HCC. Various genes have been identified to be differentially expressed in HCC tissues compared with paratumor tissues, including HIWI IGF2, FAT10, SCARA5, DLK1, p53 and ZNF267 (6-12), which have either oncogenic or tumor suppressive roles, indicating that $\mathrm{HCC}$ is based on complex oncogenic factors.

Besides oncogene activation and deregulation of apoptosis-associated genes, inactivation of tumor suppressor genes has also been associated with HCC (13). Evasion of apoptosis and angiogenesis are typical cancer-associated processes, whose reversal is an efficient therapeutic strategy for HCC (14) and other tumor types (15). Inhibitors of apoptosis (IAPs) are characterized by highly conserved baculoviral IAP repeats (16), belonging to a family of endogenous inhibitors of 
caspases $(17,18)$. X-linked IAP (XIAP) prevents the activities of caspase-3, -7 and -9 via directly binding to these caspases (19). Overexpression of XIAP has been reported in most human cancer types, including HCC, and to be an independent prognostic factor for HCC patients (20). Inhibition of XIAP induces apoptosis and inhibits the growth of HCC cells (21), implying that targeting XIAP may be a promising approach for HCC therapy. XIAP-associated factor (XAF)-1 specifically inhibits IAP and sensitizes cancer cells to apoptosis (22), resulting in a pro-apoptotic effect (23). Thus, this antagonist may have significant value in the treatment of cancer.

In the present study, a recombinant adenovirus was constructed, which carries a coding sequence for XAF-1 and another sequence encoding tumor necrosis factor (TNF)- $\alpha$, which induces apoptosis similarly to XAF-1, with the $2 \mathrm{~A}$ peptide coding sequence (24). The anti-tumor effects of this recombinant adenovirus was then assessed in HCC cells in vitro. The present study provided a novel strategy for the treatment of HCC.

\section{Materials and methods}

Tissue specimens, cell lines and culture. A total of 56 HCC intratumor specimens and 56 paired peritumor specimens (as controls; obtained at a distance of $>10 \mathrm{~mm}$ from the tumor edge) were included in the present study. All specimens were obtained from the pathological archives of Baotou Cancer Hospital (Batou, China) and had been obtained between May 2009 and June 2014 with informed consent of the patients. The HCC specimens had been obtained by surgical resection, immediately frozen in liquid nitrogen and stored at $-80^{\circ} \mathrm{C}$ prior to radiotherapy or chemotherapy. Clinico-pathological characteristics of each patient are listed in Table I. The present study was approved by the Medical Ethics Committee of Baotou Cancer Hospital (Batou, China).

The MHCC97L, HepG2 and MHCC97H human HCC cell lines and the L02 control liver cell line were purchased from the cell resource center of the Chinese Academy of Medical Sciences (Beijing, China). Each cell line was cultured in Dulbecco's modified Eagle's medium (DMEM; Ameresco, Inc., Framingham, MA, USA) with $10 \%$ fetal bovine serum (FBS; Invitrogen; Thermo Fisher Scientific, Inc., Waltham, $\mathrm{MA}, \mathrm{USA}$ ) at $37^{\circ} \mathrm{C}$ in a humidified atmosphere containing $5 \%$ $\mathrm{CO}_{2}$.

Construction of an adenovirus co-expressing XAF-1 and $T N F-\alpha(A d-X A F-1 \& T N F-\alpha)$. The open reading frame (ORF) of human XAF-1 (NM_017523) and TNF- $\alpha$ (NM_000594) was amplified by polymerase chain reaction (PCR) with primers that deleted the stop codon, and was overlapped with a sequence encoding a $2 \mathrm{~A}$ peptide linker (24). The overlapped XAF-1 - 2A - TNF- $\alpha$ nucleotide was inserted into the pShuttle-cytomegalovirus (CMV) vector (Qbiogene, Inc., Irvine, CA, USA) to generate the recombinant pShuttle-CMV - XAF-1 - 2A - TNF- $\alpha$. The adenovirus Ad-XAF- $1 \&$ TNF- $\alpha$ and the Ad-control (Ad-con) virus were enveloped via co-transfecting the pShuttle-CMV - XAF-1 - 2A - TNF- $\alpha$ and the pAdeasy-1 (the viral DNA plasmid) into 293GPG retrovirus packaging cell line (Cell Resource Center of the Chinese Academy of Medical Sciences) using
Lipofectamine $^{\mathrm{TM}} 2000$ (Invitrogen; Thermo Fisher Scientific, Inc.). To co-express XAF-1 and TNF- $\alpha$ in HCC cells, MHCC97L cells were infected with Ad-XAF-1\&TNF- $\alpha$ at a multiplicity of infection (MOI) of 1 or 10 for $2 \mathrm{~h}$, followed by culture in fresh DMEM containing $2 \%$ FBS.

$R N A$ isolation and reverse-transcription quantitative PCR $R T-q P C R$. Cellular mRNA was isolated from tissues or cell lines using TRIzol (Invitrogen; Thermo Fisher Scientific, Inc.) according to the manufacturer's manual, following homogenization of tissues. RT-qPCR was performed using the One Step SYBR ${ }^{\circledR}$ Green RT-qPCR kit (Sigma-Aldrich, St. Louis, MO, USA) following the manufacturer's instructions. The PCR reaction conditions were as follows: Initial denaturation, 5 min at $95^{\circ} \mathrm{C} ; 40$ cycles of denaturation for $20 \mathrm{sec}$ at $94^{\circ} \mathrm{C}$, annealing for $20 \mathrm{sec}$ at $61^{\circ} \mathrm{C}$ and extension for $20 \mathrm{sec}$ at $72^{\circ} \mathrm{C}$; and a final extension for $5 \mathrm{~min}$ at $72^{\circ} \mathrm{C}$. The primers for XAF-1, TNF- $\alpha$ and $\beta$-actin were synthesized by Invitrogen; Thermo Fisher Scientific, Inc., and were as follows: Forward, 5'-CCC AGGGACCTCTCTCTAATC-3' and reverse, 5'-ATGGGC TACAGGCTTGTCACT-3' for TNF- $\alpha$; forward, 5'-AGAATT CCCCATTCAGTAAG-3' and reverse, 5'-GTGTAAGGAAGT GGTTCAGT-3' for XAF-1; and forward, 5'-CATTAAGGA GAAGCTGTGCT-3' and reverse, 5'-GTTGAAGGTAGTTTC GTGGA-3' for $\beta$-actin. RT-qPCR was performed in an ABI PRISM 7000 (Applied Biosystems; Thermo Fisher Scientific, Inc.). Expression levels were normalized to the internal control $\beta$-actin, expressed as the fold change compared with the control and calculated using the $\Delta \Delta \mathrm{Ct}$ method (25), subsequent to confirm the target PCR product with melting curve analysis.

Western blot analysis. Intratumor or peritumor specimens from HCC patients were homogenized prior to protein extraction. Lysis was then performed with a Cell Lysis and Protein Extraction kit (Thermo Fisher Scientific, Inc.) according to the manufacturer's instructions, followed by addition of protease inhibitor cocktail (Sigma-Aldrich). Proteins were quanitified using the BCA Protein assay reagent kit (Thermo Fisher Scientific, Inc.) and $25 \mu \mathrm{g}$ of each sample was separated by $10 \%$ sodium dodecyl sulfate polyacrylamide gel (Thermo Fisher Scientific, Inc.) electrophoresis and then transferred onto a nitrocellulose membrane (EMD Millipore, Billerica, MA, USA). Non-specific binding was blocked with $2 \%$ bovine serum albumin (Ameresco, Inc.) overnight at $4^{\circ} \mathrm{C}$, and membranes were subsequently probed with rabbit polyclonal antibody to XAF-1 (Abcam, Cambridge, MA, USA; cat. no. ab81353; $1: 500$ dilution) $\beta$-actin (Abcam; cat. no. ab8227; 1:200 dilution) or TNF- $\alpha$ (Cell Signaling Technology Inc., Danvers, MA, USA; cat. no. $3727 ; 1: 500$ dilution) at $4^{\circ} \mathrm{C}$ overnight. The membrane was finally incubated with goat anti-rabbit horseradish peroxidase-conjugated secondary antibody (Promega Corp., Madison, WI, USA; cat. no. W4011) at $4^{\circ} \mathrm{C}$ for $2 \mathrm{~h}$, and antibodies were visualized using an enhanced chemiluminescence detection system (GE Healthcare, Little Chalfont, UK) following the manufacturer's instructions. The images of the blots were captured on a UVP BioSpectrum 500 imaging system (UVP, LLC, Upland, CA, USA) and the bands were analyzed using Image $\mathrm{J}$ (imagej.nih.gov/ij/). The protein levels of XAF-1 or TNF- $\alpha$ were expressed as a percentage to $\beta$-actin. 
Table I. Association of XAF-1 mRNA with clinico-pathological characteristics of hepatocellular carcinoma patients [mean age, $53.4 \pm 10.3$ for XAF-1 levels $\geq 1$ and $51.5 \pm 9.6$ years for XAF-1 levels $<1$ ( $\mathrm{P}=0.7620)$ ].

\begin{tabular}{|c|c|c|c|}
\hline \multirow[b]{2}{*}{ Characteristic } & \multicolumn{2}{|c|}{ XAF-1 mRNA levels } & \multirow[b]{2}{*}{ P-value } \\
\hline & $\geq 1(n=20)$ & $<1(\mathrm{n}=36)$ & \\
\hline Age (years) & & & 0.2012 \\
\hline$\geq 50$ & 13 & 17 & \\
\hline$<50$ & 7 & 19 & \\
\hline HBsAg & & & 0.1878 \\
\hline Negative & 2 & 3 & \\
\hline Positive & 8 & 13 & \\
\hline AFP & & & 0.1385 \\
\hline$\geq 200 \mathrm{ng} / \mathrm{ml}$ & 3 & 7 & \\
\hline$<200 \mathrm{ng} / \mathrm{ml}$ & 7 & 9 & \\
\hline Tumor size & & & 0.0406 \\
\hline$\geq 5 \mathrm{~cm}$ & 3 & 10 & \\
\hline$<5 \mathrm{~cm}$ & 7 & 6 & \\
\hline BCLC stage & & & 0.0470 \\
\hline $0-\mathrm{B}$ & 8 & 8 & \\
\hline C-D & 2 & 8 & \\
\hline TNM stage & & & 0.0274 \\
\hline $\mathrm{I}+\mathrm{II}$ & 8 & 7 & \\
\hline III+IV & 2 & 9 & \\
\hline Vascular invasion & & & 0.0731 \\
\hline Yes & 1 & 5 & \\
\hline No & 9 & 11 & \\
\hline
\end{tabular}

The XAF-1 mRNA levels were relative to $\beta$-actin. HBsAG, hepatitis B surface antigen; BCLC, Barcelona clinic liver cancer; TNM, tumor, nodes, metastasis; AFP, alpha-fetoprotein.

Apoptosis assay via Annexin V-fluorescein isothiocyanate (FITC)/propidium iodide (PI) kit. The apoptosis of MHCC97L cells with or without infection (1 MOI, $24 \mathrm{~h}$ ) with Ad-Con, Ad-XAF-1, Ad-TNF- $\alpha$ or Ad-XAF-1\&TNF- $\alpha$ was examined with an ApoDETECT Annexin V-FITC kit (Thermo Fisher Scientific, Inc.) according to the manufacturer's protocol. Briefly, MHCC97L cells either without or post-infection were incubated at $37^{\circ} \mathrm{C}$ for $24 \mathrm{~h}$, and then were harvested and suspended in binding buffer $\left(5 \times 10^{5}\right.$ cells $\left./ \mathrm{ml}\right)$. The suspended cells were mixed with $5 \mu 1$ Annexin V-FITC and $10 \mu \mathrm{l}$ of PI and incubated for $15 \mathrm{~min}$ in the dark at room temperature. The stained cells were detected using a FACScan flow cytometer (BD Biosciences, Franklin Lakes, NJ, USA). The results were calculated using the CellQuest ${ }^{\mathrm{TM}}$ Pro software (BD Biosciences) and were presented as the percentage of apoptotic cells to total cells.

Cell proliferation assay and colony formation assay. The proliferation of HCC cells was evaluated using a cell counting assay and a colony formation assay. The cell counting assay was performed as follows: Cells $\left(10^{3} / \mathrm{ml}\right)$ were seeded into 12 -well plates and then infected with Ad-XAF-1\&TNF- $\alpha$ or Ad-con virus at an MOI of 1 or 10 for $2 \mathrm{~h}$, followed by further incubation in medium for 1,3 or 5 days. The cells were trypsinized and the number of viable cells was counted using a hemocytometer (Reichert, Inc., Depew, NY, USA) following trypan blue (Thermo Fisher Scientific, Inc.) staining. For the colony formation assay, 1,000 cells were seeded into a 12-well plate and infected with Ad-XAF, Ad-TNF- $\alpha$, Ad-XAF-1\&TNF- $\alpha$ or Ad-con virus at an MOI of 1 or 10 for $2 \mathrm{~h}$, followed by incubation in medium for another five days. The cell colonies were stained with $0.5 \%$ crystal violet (Sigma-Aldrich) in methanol for $10 \mathrm{~min}$ and colonies were counted on the plate by the naked eye.

Statistical analysis. Values are expressed as the mean \pm standard error of the mean. Differences between two groups were evaluated using Student's unpaired $t$-test for the cell viability assay, and the paired-samples $t$-test was used for comparison of expression levels in the tumor and peri-tumor tissues or among the cell lines. Statistical analysis was performed using GraphPad Prism software (version 5; GraphPad Inc., La Jolla, CA, USA) and $\mathrm{P}<0.05$ was considered to indicate a statistically significant difference between values.

\section{Results}

$X A F-1$ is downregulated in HCC specimens and cell lines. To confirm the tumor suppressive role of XAF-1 in HCC, 
A

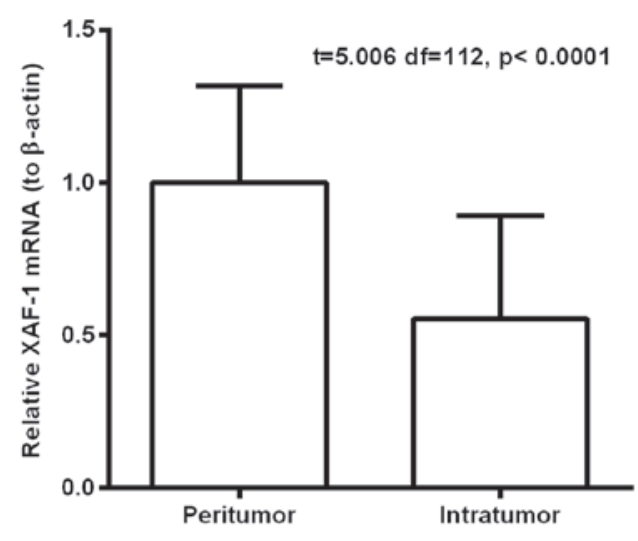

C

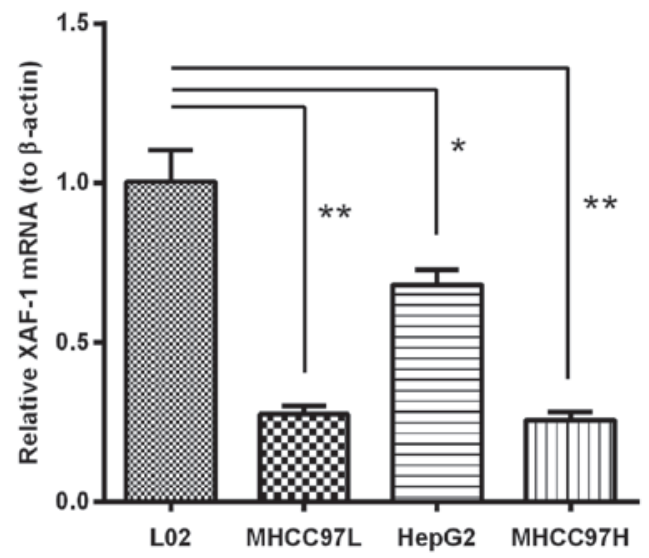

B

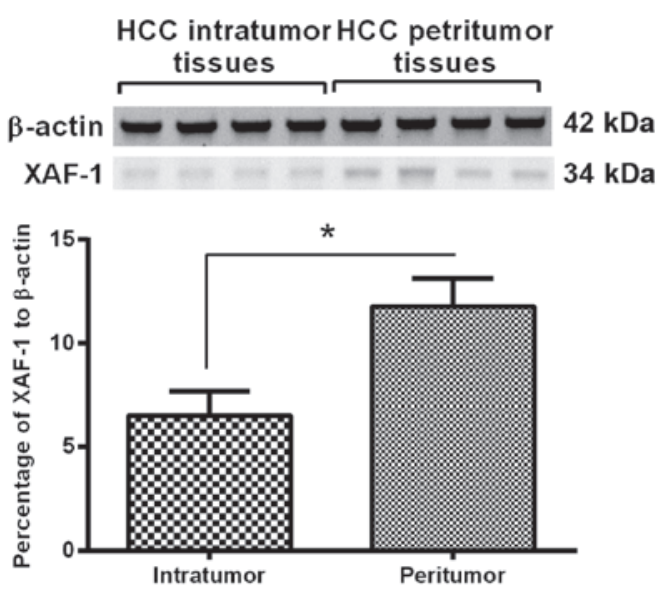

D

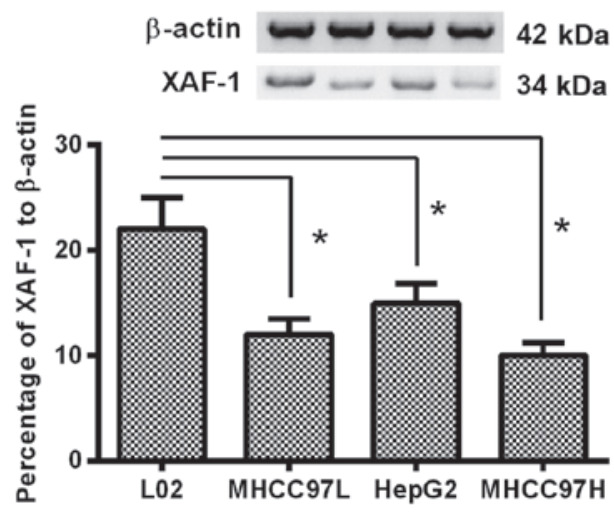

Figure 1. Reduced expression of XAF1 in HCC specimens. (A) Relative mRNA levels and (B) protein levels of XAF-1 in HCC and paired peritumor samples $(\mathrm{n}=56)$. (C) Relative mRNA levels and (D) protein levels of XAF-1 in the HCC cell lines. mRNA levels were determined by RT-qPCR analysis and protein levels were determined by western blot analysis, expression levels were normalized to $\beta$-actin. RT-qPCR and western blotting analysis were repeated in triplicate. Values are expressed as the mean \pm standard error of the mean. ${ }^{*} \mathrm{P}<0.05,{ }^{* *} \mathrm{P}<0.01$. XAF-1, X-linked inhibitor of apoptosis-associated factor 1 ; HCC, hepatocellular carcinoma; RT-qPCR, reverse-transcription quantitative polymerase chain reaction.

its expression was determined in 56 HCC specimens and paired peri-tumor tissues. As shown in Fig. 1A, compared to the levels in the peri-tumor tissues, the relative XAF-1 mRNA levels (to $\beta$-actin) in the HCC specimens were significantly reduced by $\sim 40 \%$ ( $\mathrm{P}<0.01)$. Furthermore, western blot analysis confirmed a $\sim 50 \%$ reduction of XAF-1 protein expression in the HCC group compared with that in the peri-tumor samples $(\mathrm{P}<0.001)$ (Fig. 1B). Furthermore, the expression of XAF-1 in the HCC cell lines MHCC97L, HepG2 and MHCC97H was significantly reduced at the mRNA and protein level compared to that in the L02 human hepatic cell line $(\mathrm{P}<0.05$ or $\mathrm{P}<0.01)$ (Fig. $1 \mathrm{C}$ and $\mathrm{D})$. Thus, the significant downregulation of XAF-1 in $\mathrm{HCC}$ specimens and cell lines was confirmed.

Downregulation of XAF-1 is associated with the degree of malignancy of $H C C$. To assess the association of the reduced XAF-1 with the malignant characteristics of HCC, the correlation of XAF-1 expression with clinico-pathological features, including tumor size, Barcelona clinic liver cancer (BCLC) stage, tumor -nodes -metastasis (TNM) stage and vascular invasion, was assessed. As shown in Table I, there was no significant difference in age, hepatitis B surface antigen positivity or alpha-fetoprotein levels between the groups with XAF-1 levels $<1$ and XAF-1 levels $\geq 1$. However, XAF-1 expression was negatively associated with the tumor size, BCLC stage, TMN stage ( $\mathrm{P}<0.05$, respectively). However, the association of XAF-1 mRNA levels with vascular invasion was not significant $(\mathrm{P}>0.05)$. In conclusion, these results confirmed the association of reduced XAF-1 mRNA levels with the degree of malignancy of HCC.

Construction of adenovirus co-expressing XAF-1 and $T N F-\alpha$. To further identify the suppressive role of XAF-1 in $\mathrm{HCC}$, an adenovirus co-expressing XAF-1 and TNF- $\alpha$ was constructed. XAF-1 and TNF- $\alpha$ cDNA were amplified by PCR and then linked with a $2 \mathrm{~A}$ peptide coding sequence (24). The construction strategy of the recombinant adenovirus Ad-XAF-1\&TNF- $\alpha$ was illustrated in Fig. 2A. The adenovirus expressing green fluorescence protein (Ad-con), XAF-1 (Ad-XAF-1) or TNF- $\alpha$ (Ad-TNF- $\alpha$ ) were used as controls. Each recombinant adenovirus was enveloped via co-transfection of the respective adenoviral genomic plasmid and the shuttle plasmid into BJ5183 bacterial cells. The efficiency of the adenovirus to co-express XAF-1 and TNF- $\alpha$ was evaluated in MHCC97L cells at an MOI of 1 or 10 . At $24 \mathrm{~h}$ post-infection, the mRNA levels of the two genes were significantly enhanced $(\mathrm{P}<0.01$ or $\mathrm{P}<0.0001$, respectively) 
A

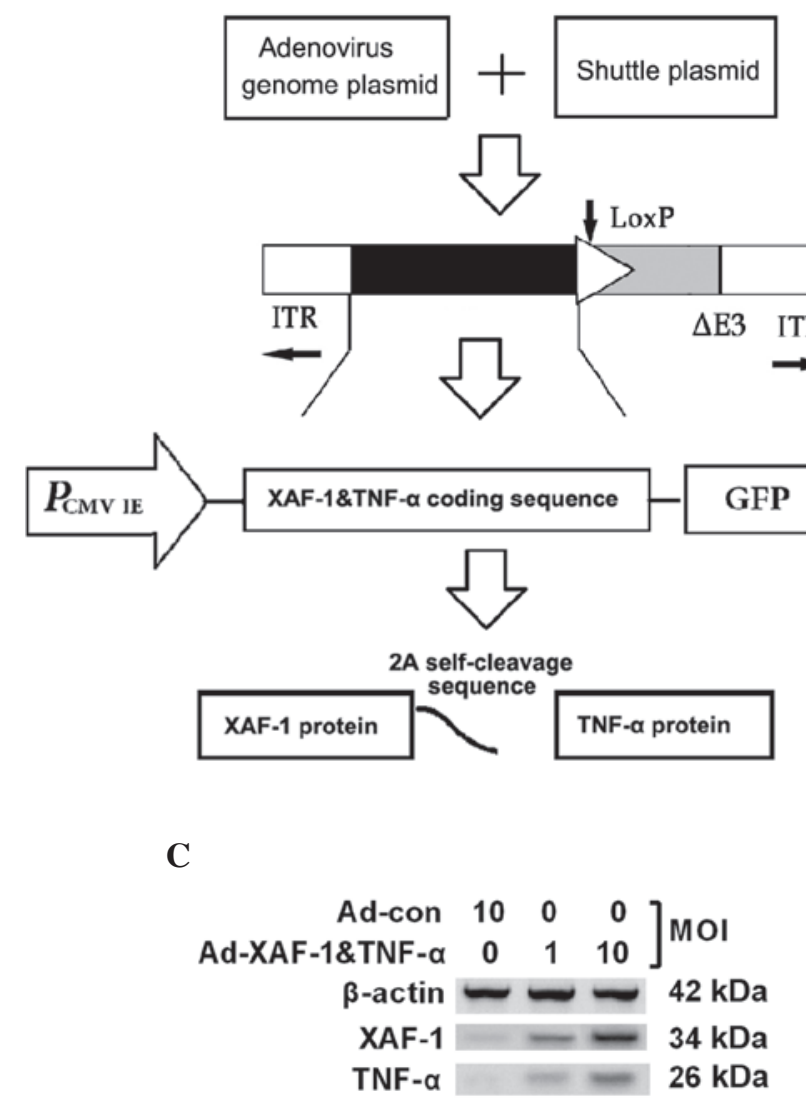

B

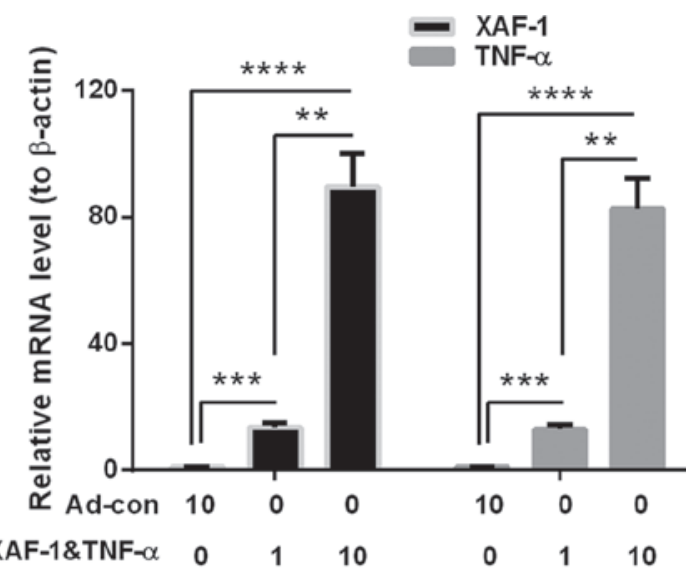

D

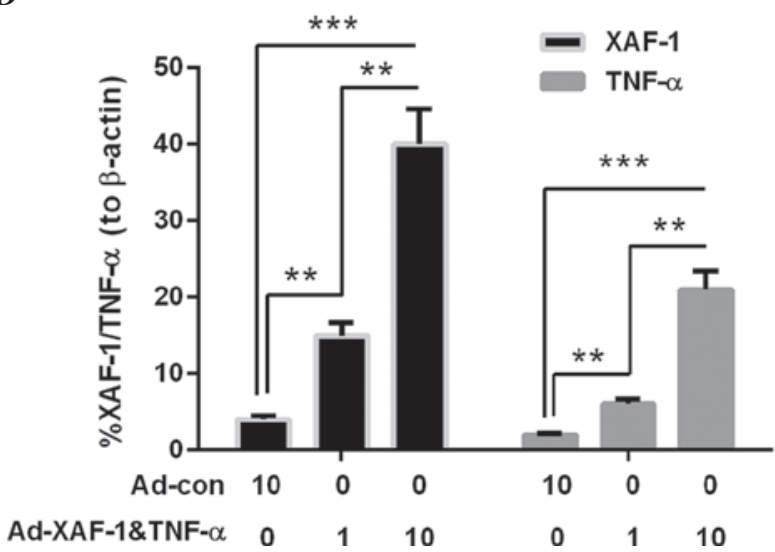

Figure 2. Construction of Ad-XAF-1\&TNF- $\alpha$ and confirmation of efficient upregulation. (A) Schematic diagram of Ad-XAF-1\&TNF- $\alpha$ with a $2 \mathrm{~A}$ peptide linker. (B) mRNA levels and (C and D) protein levels of XAF-1 and TNF- $\alpha$ in MHCC97L hepatocellular carcinoma cells infected with Ad-XAF-1\&TNF- $\alpha$ or Ad-con at an MOI of 1 or 10 for 24 h. Protein levels of XAF-1 or TNF- $\alpha$ were normalized to $\beta$-actin. Values are expressed as the mean \pm standard error of the mean for triple independent experiments. ${ }^{* *} \mathrm{P}<0.01,{ }^{* * *} \mathrm{P}<0.001$ or ${ }^{* * * * *} \mathrm{P}<0.0001$. Ad-AF-1\&TNF- $\alpha$, adenovirus for the co-expression of $\mathrm{XAF}-1$ and TNF- $\alpha$; Ad-con, control vector; ITR, inverted terminal repeat; GFP, green fluorescence protein; CMV, cytomegalovirus; TNF, tumor necrosis factor; XAF-1, X-linked inhibitor of apoptosis-associated factor 1; MOI, multiplicity of infection.

(Fig. 2B). Furthermore, western blot analysis indicated that the protein levels of XAF-1 and TNF- $\alpha$ were significantly enhanced by the adenovirus $(\mathrm{P}<0.01, \mathrm{P}<0.001$ or $\mathrm{P}<0.0001)$ (Fig. 2C and D).

In addition, to compare the effects of Ad-XAF-1\&TNF- $\alpha$ with those of XAF-1 or TNF- $\alpha$ alone, MHCC97L cells were infected with Ad-XAF-1 or Ad-TNF- $\alpha$. As expected, XAF-1 was only overexpressed following infection with Ad-XAF-1, while TNF- $\alpha$ was only overexpressed following infection with Ad-TNF- $\alpha$ at the mRNA and protein level $(\mathrm{P}<0.001)$, while Ad-con had no effect (Fig. 3). While XAF-1 as well as TNF- $\alpha$ were significantly overexpressed following infection with Ad-XAF-1\&TNF- $\alpha(\mathrm{P}<0.001)$, their expression levels were significantly lower than those following infection with the respective mono-overexpression vectors.

In addition, apoptosis in the MHCC97L cells that were infected with 1 MOI Ad-Con, Ad-XAF-1, Ad-TNF- $\alpha$ or Ad-XAF-1\&TNF- $\alpha$ was examined. MHCC97L cells without infection served as a blank control. As indicated in Fig. 3D and E), compared with the Ad-Con, Ad-XAF-1 or Ad-TNF- $\alpha$ induced a significantly increased level of apoptosis in MHCC97L cells $(\mathrm{P}<0.05$ or $\mathrm{P}<0.01)$. Furthermore, the Ad-XAF-1\&TNF- $\alpha$ infection induced more apoptotic cells than the infection with Ad-XAF-1 or Ad-TNF- $\alpha(\mathrm{P}<0.01)$. Thus, the co-expression of XAF-1 and TNF- $\alpha$ synergistically induced apoptosis in MHCC97L cells.

Co-expression of XAF-1 and TNF- $\alpha$ inhibits the growth of HCC cells. The present study then investigated the effects of XAF-1 and TNF- $\alpha$ co-expression on the growth of HCC cells. The growth of MHCC97L cells was assessed in vitro using a cell counting assay and a colony formation assay. It was revealed that following infection with Ad-XAF-1\&TNF- $\alpha$, the proliferation of MHCC $97 \mathrm{~L}$ cells was reduced compared with that of the cells infected with Ad-con, Ad-XAF-1 or Ad-TNF- $\alpha$ at either 3 days $(\mathrm{P}<0.05$ or $\mathrm{P}<0.001)$ or 5 days $(\mathrm{P}<0.05, \mathrm{P}<0.01$ or $\mathrm{P}<0.001)$ post-infection, while infection with Ad-XAF-1 or Ad-TNF- $\alpha$ also significantly inhibited the proliferation of MHCC 97L cells ( $\mathrm{P}<0.05$ or $\mathrm{P}<0.01)$ (Fig. 4A and B). Similarly, the colony formation assay showed that the clonogenicity of MHCC97L cells following infection with Ad-XAF-1\&TNF- $\alpha$ was significantly reduced compared with that following infection with Ad-XAF-1 or Ad-TNF- $\alpha$ ( $\mathrm{P}<0.05$; Fig. 4C and D), while mono-infection still significantly reduced the number of colonies formed ( $\mathrm{P}<0.05$ or $\mathrm{P}<0.01$; Fig. $4 \mathrm{C}$ and $\mathrm{D})$. These results indicated that co-expression of XAF-1 and TNF- $\alpha$ 
A

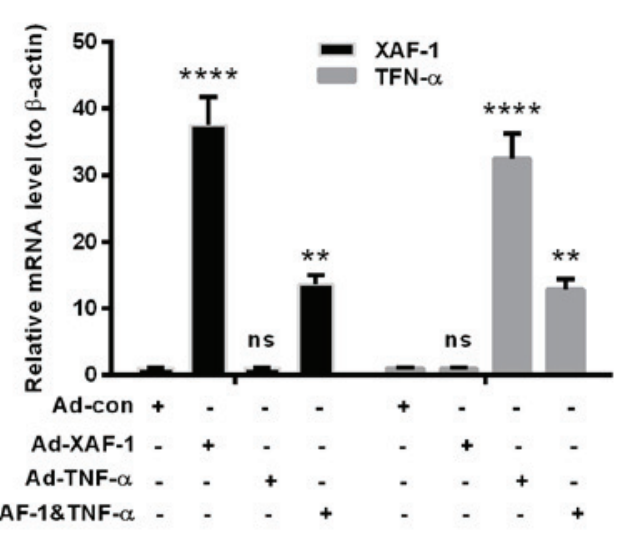

C

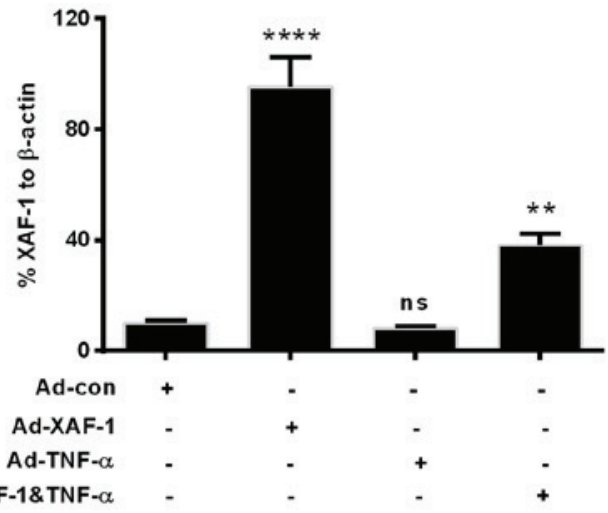

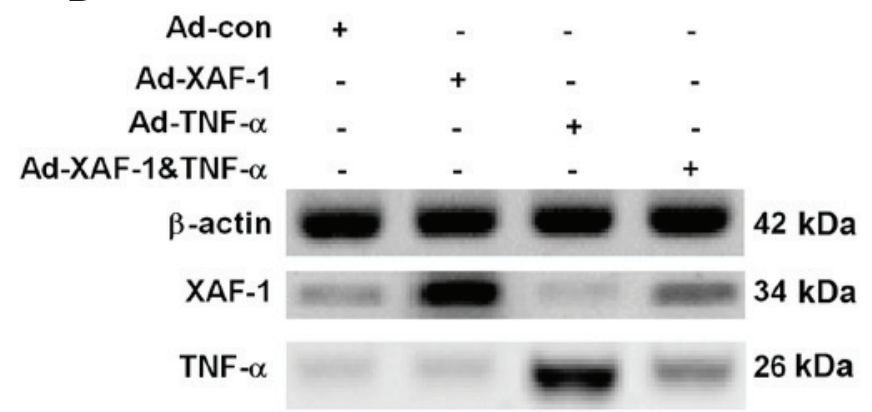

D

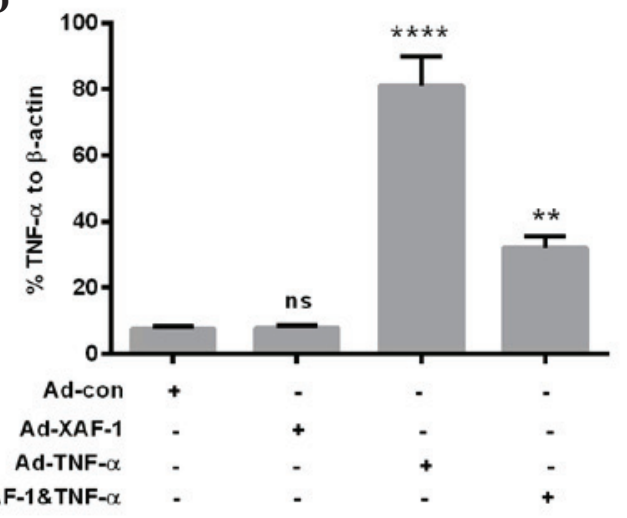

E

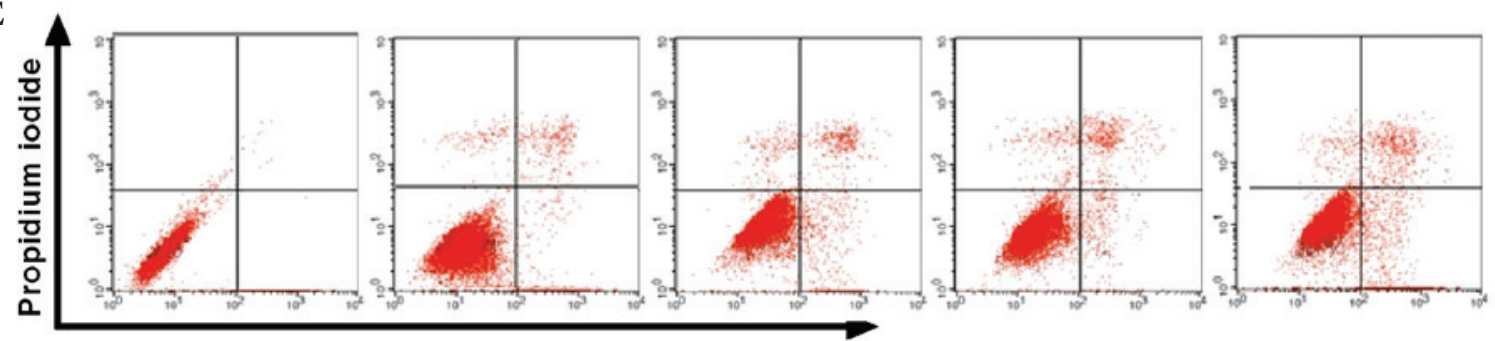

Annexin V-FITC

F

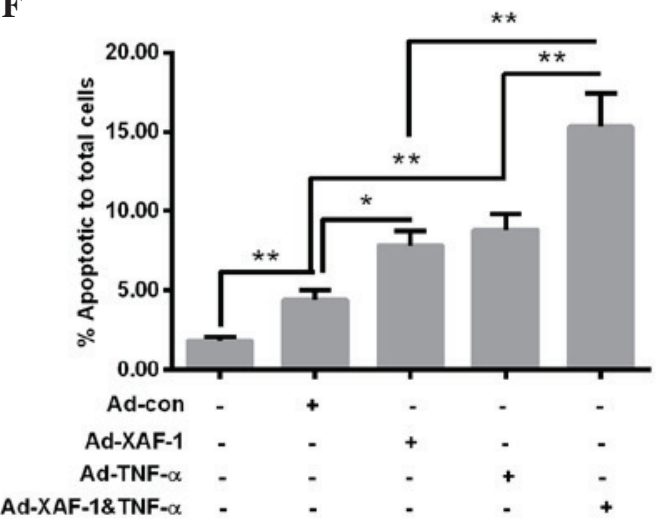

Figure 3. Overexpression of XAF1, TNF- $\alpha$ and their combination in hepatocellular carcinoma cells. (A) mRNA levels and (B-D) protein levels of XAF-1 and TNF- $\alpha$ in the MHCC97L cell line following infection with Ad-XAF-1\&TNF- $\alpha$, Ad-XAF or Ad-TNF- $\alpha$ at a multiplicity of infection of 1 for 24 h. The levels of XAF-1 or TNF- $\alpha$ were normalized to $\beta$-actin. (E) Representative flow cytometry assay and (F) the percentage of apoptotic MHCC97L cells following infection. MHCC $97 \mathrm{~L}$ cells without infection served as a blank control. Values are expressed as the mean \pm standard error of the mean for triple independent experiments. ${ }^{*} \mathrm{P}<0.05,{ }^{* *} \mathrm{P}<0.01$ or ${ }^{* * * * *} \mathrm{P}<0.0001$; ns, not significant; Ad-AF-1\&TNF- $\alpha$, adenovirus for the co-expression of XAF-1 and TNF- $\alpha$; Ad-con, control vector; TNF, tumor necrosis factor; XAF-1, X-linked inhibitor of apoptosis-associated factor 1.

inhibited the growth of HCC MHCC97L cells more efficiently than either protein alone, even though their co-expression was lower than that following infection with Ad-XAF-1 or Ad-TNF- $\alpha$. 
A

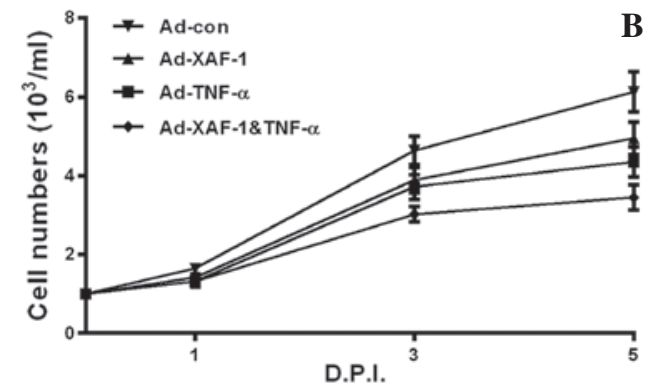

B

\begin{tabular}{|l|c|c|c|c|c|}
\hline Categories & Ad-con & Ad-XAF-1 & Ad-TNF- $\alpha$ & Ad-XAF-1\&TNF- $\alpha$ & \multicolumn{2}{|c|}{} \\
\hline Ad-con & $\backslash$ & $*$ & $* *$ & $* * * *$ & 3 D.P.I. \\
\hline Ad-XAF-1 & $*$ & $\backslash$ & ns & $* *$ & 5 D.P.I. \\
\hline Ad-TNF- $\alpha$ & $*$ & ns & $\backslash$ & $*$ & \\
\hline Ad-XAF-1\&TNF- $\alpha$ & $* * *$ & $*$ & $*$ & $\backslash$ \\
\hline
\end{tabular}
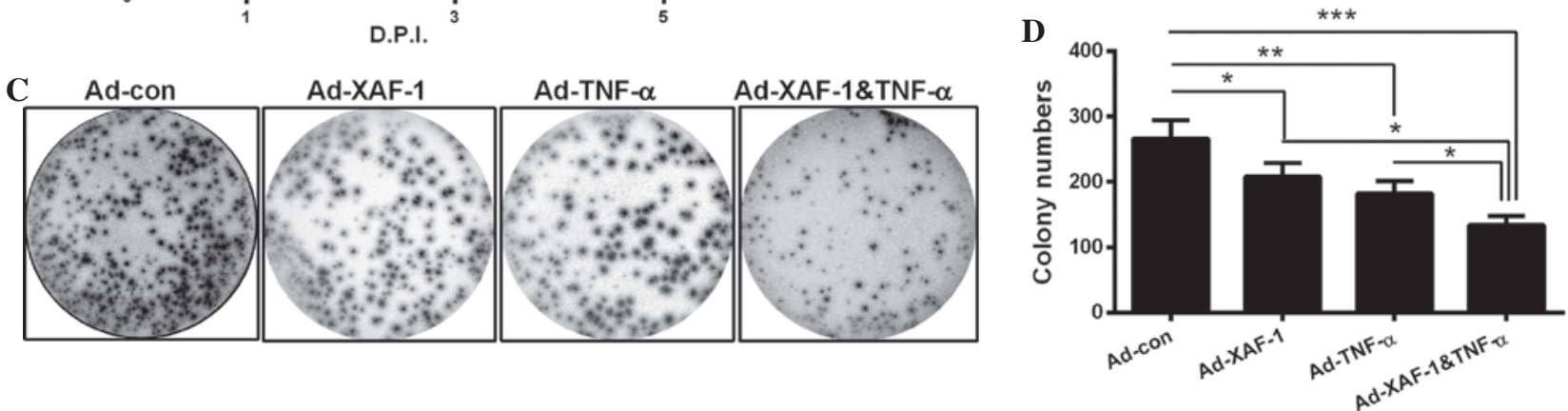

Figure 4. Co-expression of XAF1 and TNF- $\alpha$ by Ad-XAF-1\&TNF- $\alpha$ inhibits the growth of hepatocellular carcinoma cells. (A) Transfection with Ad-XAF-1\&TNF- $\alpha$ significantly reduced the number of viable MHCC97L cells compared with Ad-con, Ad-XAF or Ad-TNF- $\alpha$ day five according to a Trypan blue staining assay. (B) Statistical analysis of differences between cell numbers in each group using the unpaired $t$-test. (C and D) A colony formation assay demonstrated that Ad-XAF-1\&TNF- $\alpha$ significantly reduced the cologenicity of MHCC97L cells compared with Ad-con, Ad-XAF or Ad-TNF- $\alpha$. Values are expressed as the mean \pm standard error of the mean from three independent replicates. ${ }^{*} \mathrm{P}<0.05,{ }^{* * *} \mathrm{P}<0.01,{ }^{* * * *} \mathrm{P}<0.001$, or ${ }^{* * * * *} \mathrm{P}<0.0001$. ns, not significant; Ad-AF-1\&TNF- $\alpha$, adenovirus for the co-expression of XAF-1 and TNF- $\alpha$; Ad-con, control vector; TNF, tumor necrosis factor; XAF-1, X-linked inhibitor of apoptosis-associated factor 1; D.P. I, days post-infection.

\section{Discussion}

XAF-1 has been identified as a tumor suppressor gene (8) and has been reported to be deregulated in gastric (26), renal (27), pancreatic (28) and esophageal (29) cancers as well as in HCCs (14). The present study reconfirmed the downregulation of XAF-1 in HCCs at the mRNA as well as at the protein level, which was demonstrated in HCC tissues and paired peritumor specimens as well as in cell lines. Of note, the downregulation of XAF-1 was associated with the degree of malignancy of HCC, as a significant correlation of XAF-1 downregulation with the clinico-pathological characteristics of tumor size, BCLC stage and TMN stage was identified. However, the association of XAF-1 mRNA level with the vascular invasion was not significant, possibly due to the small sample size.

XAF-1 has been shown to inhibit the proliferation of lung cancer cells (30), to suppress colon cancer growth and trigger tumor regression (31), and to induce cell apoptosis in gastric and colorectal cancer cell lines; furthermore, XAF-1 was reported to enhance the apoptotic effects of chemotherapeutic drugs and TNF-related apoptosis-inducing ligand $(31,32)$. Recombinant adenoviral vector-mediated $\mathrm{XAF}-1$ overexpression was previously shown to significantly suppress tumor growth in gastric and colon cancer in vitro and in vivo (14,31-34). The present study confirmed that the co-expression of XAF-1 and TNF- $\alpha$ by the Ad-XAF-1\&TNF- $\alpha$ infection synergistically induced apoptosis in the HCC MHCC97L cells and inhibited the proliferation of HCC cells. To amplify the inhibitory effects of XAF-1 on HCC cell growth, a co-expressing strategy was utilized to overexpress XAF- 1 and TNF- $\alpha$ by a singular adenovirus with a $2 \mathrm{~A}$ peptide linker.
The 2A peptide is a 'self-cleavage' peptide, which is encoded by the foot-and-mouth disease virus. The $2 \mathrm{~A}$ peptide links two coding sequences in one ORF, which is transcribed into one mRNA molecule, whereas it is translated into two different, function-independent proteins (24). The 'self-cleavage' characteristic of $2 \mathrm{~A}$ peptide qualifies it to co-express two separate molecules by same vector efficiently $(35,36)$. The present study was the first to constructed an adenovirus, Ad-XAF-1\&TNF- $\alpha$, which co-expressed XAF-1 and TNF- $\alpha$ efficiently. The expression of the two genes was significantly increased at the mRNA as well as the protein level by infection of the Ad-XAF-1\&TNF- $\alpha$ into HCC MHCC97L cells. Furthermore, infection with Ad-XAF-1\&TNF- $\alpha$ significantly reduced the proliferation and clonogenicity of HCC MHCC97L cells to a greater extent than infection with the Ad-XAF-1 or Ad-TNF- $\alpha$ virus individually. The present study provides a method by which XAF-1 and TNF- $\alpha$ were expressed simultaneously per transcription. The co-expression vector presents an advantage as a potential anti-tumor strategy, as a single administration simultaneously presents two different anti-tumor effectors in the same tumor cell.

In conclusion, the present study was the first to construct an adenovirus which co-expressed XAF-1 and TNF- $\alpha$ in same ORF and expressed them proportionally. This Ad-XAF-1\&TNF- $\alpha$ co-expression virus inhibited the proliferation of $\mathrm{HCC}$ cells more efficiently than infection with Ad-XAF-1 or Ad-TNF- $\alpha$ alone, suggesting that it may be a promising therapeutic for the treatment of HCC.

\section{Acknowledgements}

The present study was supported by a grant from the Baotou Bureau of Science and Technology (grant no. 2012-BT039. 


\section{References}

1. Aravalli RN, Steer CJ and Cressman EN: Molecular mechanisms of hepatocellular carcinoma. Hepatology 48: 2047-2063, 2008.

2. Niu J, Lin Y, Guo Z, Niu M and Su C: The epidemiological investigation on the risk factors of hepatocellular carcinoma: A case-control study in Southeast China. Medicine (Baltimore) 95: e2758, 2016

3. Schafer DF and Sorrell MF: Hepatocellular carcinoma. Lancet 353: 1253-1257, 1999.

4. Thorgeirsson SS and Grisham JW: Molecular pathogenesis of human hepatocellular carcinoma. Nat Genet 31: 339-346, 2002.

5. Llovet JM, Burroughs A and Bruix J: Hepatocellular carcinoma. Lancet 362: 1907-1917, 2003.

6. Huang J, Zhang X, Zhang M, Zhu JD, Zhang YL, Lin Y, Wang KS, Qi XF, Zhang Q, Liu GZ, et al: Up-regulation of DLK1 as an imprinted gene could contribute to human hepatocellular carcinoma. Carcinogenesis 28: 1094-1103, 2007.

7. Huang J, Zheng DL, Qin FS, Cheng N, Chen H, Wan BB, Wang YP, Xiao HS and Han ZG: Genetic and epigenetic silencing of SCARA5 may contribute to human hepatocellular carcinoma by activating FAK signaling. J Clin Invest 120: 223-241, 2010.

8. Iizuka N, Oka M, Yamada-Okabe H, Mori N, Tamesa T, Okada T, Takemoto N, Tangoku A, Hamada K, Nakayama H, et al: Comparison of gene expression profiles between hepatitis $\mathrm{B}$ virus- and hepatitis $C$ virus-infected hepatocellular carcinoma by oligonucleotide microarray data on the basis of a supervised learning method. Cancer Res 62: 3939-3944, 2002.

9. Okada T, Iizuka N, Yamada-Okabe H, Mori N, Tamesa T, Takemoto N, Tangoku A, Hamada K, Nakayama H, Miyamoto T, et al: Gene expression profile linked to p53 status in hepatitis $C$ virus-related hepatocellular carcinoma. FEBS Lett 555: 583-590, 2003.

10. Oliva J, Bardag-Gorce F, French BA, Li J, McPhaul L, Amidi F, Dedes J, Habibi A, Nguyen S and French SW: Fat10 is an epigenetic marker for liver preneoplasia in a drug-primed mouse model of tumorigenesis. Exp Mol Pathol 84: 102-112, 2008.

11. Schnabl B, Valletta D, Kirovski G and Hellerbrand C: Zinc finger protein 267 is up-regulated in hepatocellular carcinoma and promotes tumor cell proliferation and migration. Exp Mol Pathol 91: 695-701, 2011.

12. Jiang J, Zhang H, Tang Q, Hao B and Shi R: Expression of HIWI in human hepatocellular carcinoma. Cell Biochem Biophys 61: 53-58, 2011.

13. Jain S, Singhal S, Lee P and Xu R: Molecular genetics of hepatocellular neoplasia. Am J Transl Res 2: 105-118, 2010.

14. Zhu LM, Shi DM, Dai Q, Cheng XJ, Yao WY, Sun PH, Ding Y, Qiao MM, Wu YL, Jiang SH and Tu SP: Tumor suppressor XAF1 induces apoptosis, inhibits angiogenesis and inhibits tumor growth in hepatocellular carcinoma. Oncotarget 5: 5403-5415, 2014.

15. Henry LR, Lee HO, Lee JS, Klein-Szanto A, Watts P, Ross EA, Chen WT and Cheng JD: Clinical implications of fibroblast activation protein in patients with colon cancer. Clin Cancer Res 13: 1736-1741, 2007

16. Salvesen GS and Duckett CS: IAP proteins: Blocking the road to death's door. Nat Rev Mol Cell Biol 3: 401-410, 2002.

17. Yang YL and Li XM: The IAP family: Endogenous caspase inhibitors with multiple biological activities. Cell Res 10: 169-177, 2000

18. Ngan CY, Yamamoto H, Seshimo I, Tsujino T, Man-i M, Ikeda JI, Konishi K, Takemasa I, Ikeda M, Sekimoto M, et al: Quantitative evaluation of vimentin expression in tumour stroma of colorectal cancer. Br J Cancer 96: 986-992, 2007.

19. Zhu L, Cheng X, Ding Y, Shi J, Jin H, Wang H, Wu Y, Ye J, Lu Y, Wang TC, et al: Bone marrow-derived myofibroblasts promote colon tumorigenesis through the IL-6/JAK2/STAT3 pathway. Cancer Lett 343: 80-89, 2014.
20. Wu WY, Kim H, Zhang CL, Meng XL and Wu ZS: Clinical significance of autophagic protein LC3 levels and its correlation with XIAP expression in hepatocellular carcinoma. Med Oncol 31: 108, 2014.

21. Pan Q, Liu B, Liu J, Cai R, Liu X and Qian C: Synergistic antitumor activity of XIAP-shRNA and TRAIL expressed by oncolytic adenoviruses in experimental HCC. Acta Oncol 47: 135-144, 2008.

22. Plenchette S, Cheung $\mathrm{HH}$, Fong WG, LaCasse EC and Korneluk RG: The role of XAF1 in cancer. Curr Opin Investig Drugs 8: 469-476, 2007.

23. Leaman DW, Chawla-Sarkar M, Vyas K, Reheman M, Tamai K, Toji S and Borden EC: Identification of X-linked inhibitor of apoptosis-associated factor-1 as an interferon-stimulated gene that augments TRAIL Apo2L-induced apoptosis. J Biol Chem 277: 28504-28511, 2002.

24. Szymczak AL, Workman CJ, Wang Y, Vignali KM, Dilioglou S, Vanin EF and Vignali DA: Correction of multi-gene deficiency in vivo using a single 'self-cleaving' $2 \mathrm{~A}$ peptide-based retroviral vector. Nat Biotechnol 22: 589-594, 2004

25. Schmittgen TD and Livak KJ: Analyzing real-time PCR data by the comparative C(T) method. Nat Protoc 3: 1101-1108, 2008.

26. Wang J, Gu Q, Li M, Zhang W, Yang M, Zou B, Chan S, Qiao L, Jiang B, Tu S, et al: Identification of XAF1 as a novel cell cycle regulator through modulating $\mathrm{G}(2) / \mathrm{M}$ checkpoint and interaction with checkpoint kinase 1 in gastrointestinal cancer. Carcinogenesis 30: 1507-1516, 2009.

27. Kempkensteffen C, Fritzsche FR, Johannsen M, Weikert S, Hinz S, Dietel M, Riener MO, Moch H, Jung K, Krause H, et al: Down-regulation of the pro-apoptotic XIAP associated factor-1 (XAF1) during progression of clear-cell renal cancer. BMC Cancer 9: 276, 2009.

28. Huang J, Yao WY, Zhu Q, Tu SP, Yuan F, Wang HF, Zhang YP and Yuan YZ: XAF1 as a prognostic biomarker and therapeutic target in pancreatic cancer. Cancer Sci 101: 559-567, 2010.

29. Chen XY,He QY and Guo MZ: XAF1 is frequently methylated in human esophageal cancer. World J Gastroenterol 18: 2844-2849, 2012.

30. Yang WT, Chen DL, Zhang FQ, Xia YC, Zhu RY, Zhou DS and Chen YB: Experimental study on inhibition effects of the XAF1 gene against lung cancer cell proliferation. Asian Pac J Cancer Prev 15: 7825-7829, 2014.

31. Tu SP, Sun YW, Cui JT, Zou B, Lin MC, Gu Q, Jiang SH, Kung HF, Korneluk RG and Wong BC: Tumor suppressor XIAP-Associated factor 1 (XAF1) cooperates with tumor necrosis factor-related apoptosis-inducing ligand to suppress colon cancer growth and trigger tumor regression. Cancer 116: 1252-1263, 2010.

32. Tu SP, Liston P, Cui JT, Lin MC, Jiang XH, Yang Y, Gu Q, Jiang SH, Lum CT, Kung HF, et al: Restoration of XAF1 expression induces apoptosis and inhibits tumor growth in gastric cancer. Int J Cancer 125: 688-697, 2009.

33. Sun PH, Zhu LM, Qiao MM, Zhang YP, Jiang SH, Wu YL and Tu SP: The XAF1 tumor suppressor induces autophagic cell death via upregulation of Beclin-1 and inhibition of Akt pathway. Cancer Lett 310: 170-180, 2011

34. Qi R, Gu J, Zhang Z, Yang K, Li B, Fan J, Wang C, He Z, Qiao L, Lin $Z$ and Liu XY: Potent antitumor efficacy of XAF1 delivered by conditionally replicative adenovirus vector via caspase-independent apoptosis. Cancer Gene Ther 14: 82-90, 2007.

35. De Giorgi M, Cinti A, Pelikant-Małecka I, Chisci E, Lavitrano M, Giovannoni R and Smolenski RT: Co-expression of functional human heme oxygenase 1 , ecto-5'-nucleotidase and ecto-nucleoside triphosphate diphosphohydrolase-1 by 'self-cleaving' 2A peptide system. Plasmid 79: 22-29, 2015.

36. Chng J, Wang T, Nian R, Lau A, Hoi KM, Ho SC, Gagnon P Bi X and Yang Y: Cleavage efficient 2A peptides for high level monoclonal antibody expression in CHO cells. MAbs 7: 403-412, 2015. 